\title{
PROPERTIES OF LASER WELDS ON TRIP STEEL AFTER DEEP DRAWING
}

\author{
Iždinská Zita ${ }^{1}$, Švec Pavol ${ }^{1}$, Ďuríček Dušan ${ }^{1}$
}

${ }^{1}$ Institute of Technologies and Materials, Faculty of Mechanical Engineering, Slovak University of Technology in Bratislava, Pionierska 15, 83102 Bratislava, Slovak Republic, zita.izdinska@stuba.sk

Keywords: Tailor-welded blanks, laser welding, TRIP steel, microstructure, hardness profile

\begin{abstract}
The effect of straining was investigated on laser welded composite semiproduct which was stamped at deep drawing. Three specimens with various strain values were taken from the drawn cup and studied by means of light microscopy, transmission electron microscopy and hardness profile measurements. Higher deformation imposed higher mechanical strengthening of the base metal, heat affected zone and of the fusion zone. Fusion zone strengthening was less intensive which can be attributed to the initial fusion zone structure predominantly composed of martensite.
\end{abstract}

\section{INTRODUCTION}

The vision for medium class car with fuel consumption 2.6 litres per $100 \mathrm{~km}$ could be achieved mainly by making cars of modern new-developed high-strength steels with non-standard properties. The concept of producing composite blanks with tailored combinations of different thicknesses, strength, grades and coated/uncoated steel provides the body engineer with the option of localized property variations wherever he wants them. More often the blanks are now laser welded giving a narrow joint with minimum of distortion.

The lasers offer significant advantages such as high strength of weld joints, excellent finish simplicity, flexibility and reliability in manufacturing compared to other processes. Introduction of solid-state lasers that exceed by their parameters the older $\mathrm{CO}_{2}$ gas lasers, into the industry provide considerably higher efficiency of electric power transfer to laser beam power, higher focus ability, improved flexibility and stability of output parameters, and considerable possibilities to affect metallurgical processes [1].

TRIP (Transformation Induced Plasticity) steels, already used in many production cars, derive their strength properties from transformation of their retained austenitic fraction to martensite during forming and also on impact. The microstructure of these steels typically consists of polygonal ferrite, bainite, martensite, and retained austenite (about 5-20\%). Developments of this grade by quenching and partitioning technology now being researched should ensure higher strength levels or improved formability [2].

The main objective of this paper is the study of the effects of laser welding and successive weld straining by deep drawing on the final microstructures of base metal, heat affected zone (HAZ) and fusion zone of high strength TRIP steel. For this purpose $8 \mathrm{~kW}$ solid state laser was 
employed. The microstructures of three differently strained weld joint specimens are discussed with respect to the possibility of TRIP effect occurrence.

\section{EXPERIMENTAL}

The chemical composition and mechanical properties of the investigated advanced high strength low carbon TRIP steel (AHSS) are given in Table 1 and Table 2.

Table 1: Chemical composition of AHSS TRIP 780

\begin{tabular}{|c|c|c|c|c|c|c|c|c|c|}
\hline Component & $\mathbf{C}$ & $\mathbf{M n}$ & $\mathbf{S i}$ & $\mathbf{P}$ & $\mathbf{S}$ & $\mathbf{A l}$ & $\mathbf{N}$ & $\mathbf{C u}$ & $\mathbf{N i}$ \\
\hline [wt.\%] & 0.0113 & 1.649 & 1.237 & 0.011 & 0.001 & 0.055 & 0.0043 & 0.012 & 0.013 \\
\hline Component & $\mathbf{C r}$ & $\mathbf{A s}$ & $\mathbf{T i}$ & $\mathbf{V}$ & $\mathbf{N b}$ & $\mathbf{M o}$ & $\mathbf{S n}$ & $\mathbf{C a}$ & $\mathbf{O}$ \\
\hline [wt.\%] & 0.032 & 0.002 & 0.007 & 0.004 & 0.004 & 0.002 & 0.002 & 0.0005 & 0.0031 \\
\hline
\end{tabular}

Table 2: Mechanical properties of AHSS TRIP 780

\begin{tabular}{|c|c|c|}
\hline Ultimate tensile strength, (MPa) & Yield strength, (MPa) & Elongation, (\%) \\
\hline 825 & 435 & 24 \\
\hline
\end{tabular}

Two TRIP steel strips of the same composition but different thickness 1.2 and $1.0 \mathrm{~mm}$, were laser welded by fiber solid state TRUMF laser with the beam $0.7 \mathrm{~mm}$ in diameter and the modulated power to $8 \mathrm{~kW}$, in Arcelor Mittal Slovakia Company. Butt welding was conducted with full penetration (thus ensuring nearly 2D heat flow in the sheet). Welded composite semiproduct was subsequently stamped at deep drawing. Three representative transverse specimens with various strain levels were taken from the drawn cup. The locality of the samples cut out is shown in Fig.1. The strain levels of these samples were defined by the circular deformation pattern method [2]. On the base of this method the strain $(\varphi)$ of the specimen No.1 in the middle of weld joint was 0.002 , the strain of the experimental specimen No.2 was 0.13 and the strain of experimental specimen No.3 was 0.15 .
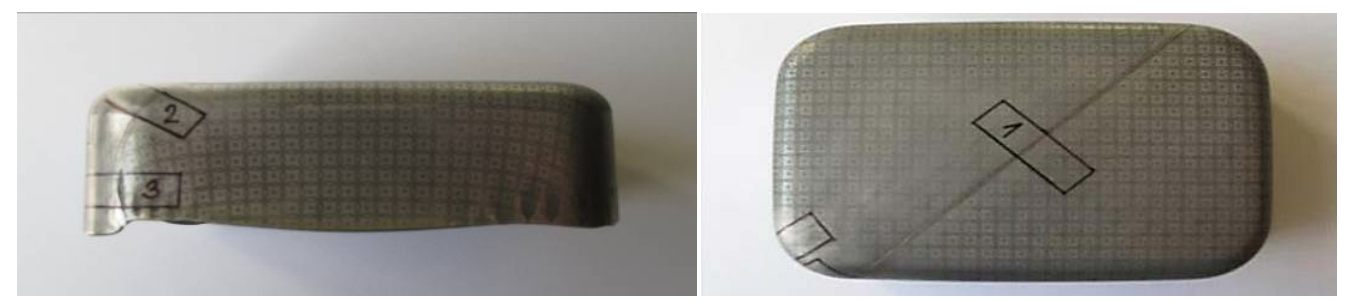

Figure1: Scheme of cut out experimental specimens

Cut out specimens were mounted, polished etched and then examined by optical microscopy. X ray diffraction apparatus Bruker Axs D8 ADVANCE with linear semiconductor detector LynxEye was used for ratio amount of phases in base metal evaluation. Transmission 
electron microscopy (TEM) was also employed to identify fusion zone microstructure. Vickers microhardness testing was carried out at load of $0.981 \mathrm{~N}(100 \mathrm{~g})$. Observations were performed with the aim to determine the strain effect on weld joint properties, whereby the possibility of TRIP effect occurrence by highest strain would be observed.

\section{RESULTS AND DISCUSSION}

The macrostructure of laser welded joint is shown in Fig. 2. Dissimilar thickness of steel sheets can be seen. Weld defects such as cracks were prominently absent.

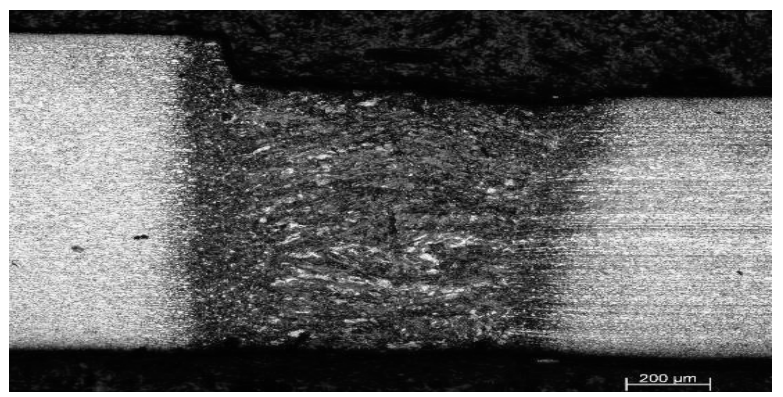

Figure 2: Laser welded joint macrostructure. $50 x$

Optical micrographs of weld metal, HAZ and base metal of the welds after deep drawing with different strain levels are given in Figs. 3 - 5.
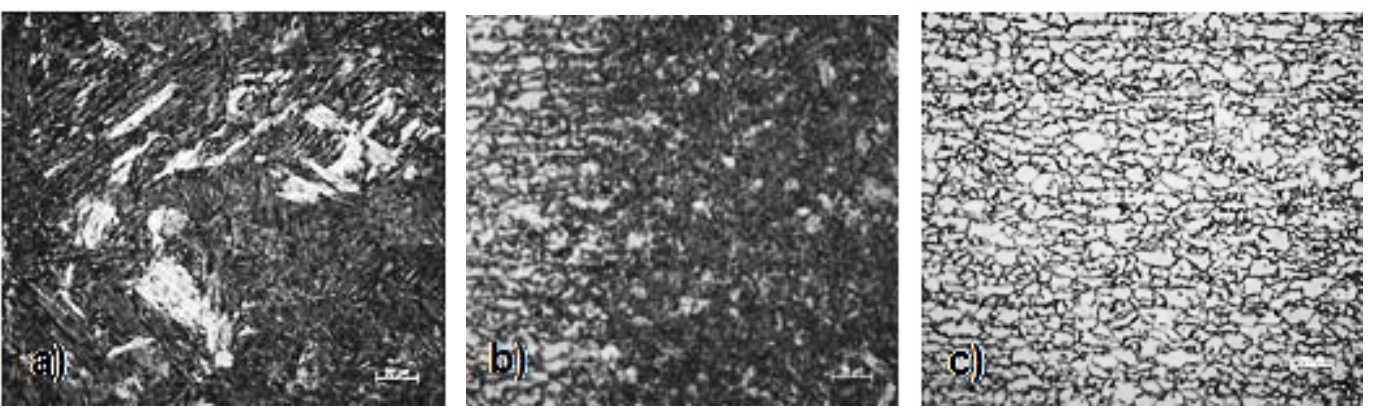

Figure 3: Optical micrographs of TRIP $780 \varphi=0.002$ a) fusion zone, b) HAZ, c) base metal. $50 x$
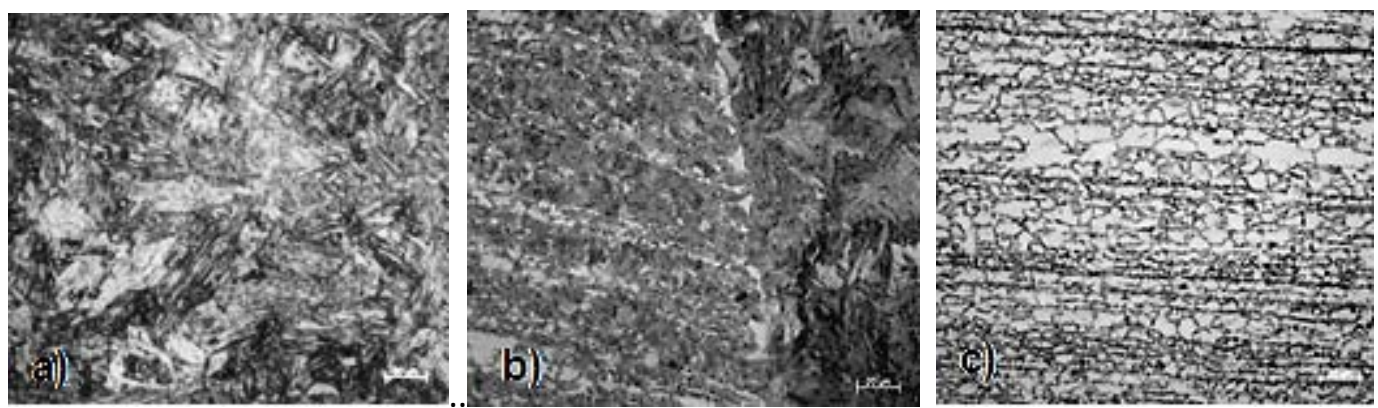

Figure 4: Optical micrographs of TRIP $780 \varphi=0.13$ a) fusion zone, b) HAZ, c) base metal. $50 x$ 
Fig. 3 documents the weld joint microstructure with the strain $\varphi=0.002$. The microstructure of fusion zone is characterized by coarse-grained martensite. The microstructure of HAZ was fine, composed of matrensite, bainite and ferrite [3]. The microstructure of specimen with higher strain $\varphi=0.012$ is in Fig. 4. Higher deformation is presented by elongated shape of ferrite grains in Fig. 4c. Marked difference of base metal structure morphology after the highest deformation is visible in Fig. 5c. As shown in Fig. $4 \mathrm{~b}$ phase transition between HAZ and base metal is smooth but on the other side in the area of thinner sheet the boundary between HAZ and base metal is visible with obvious phase border line.
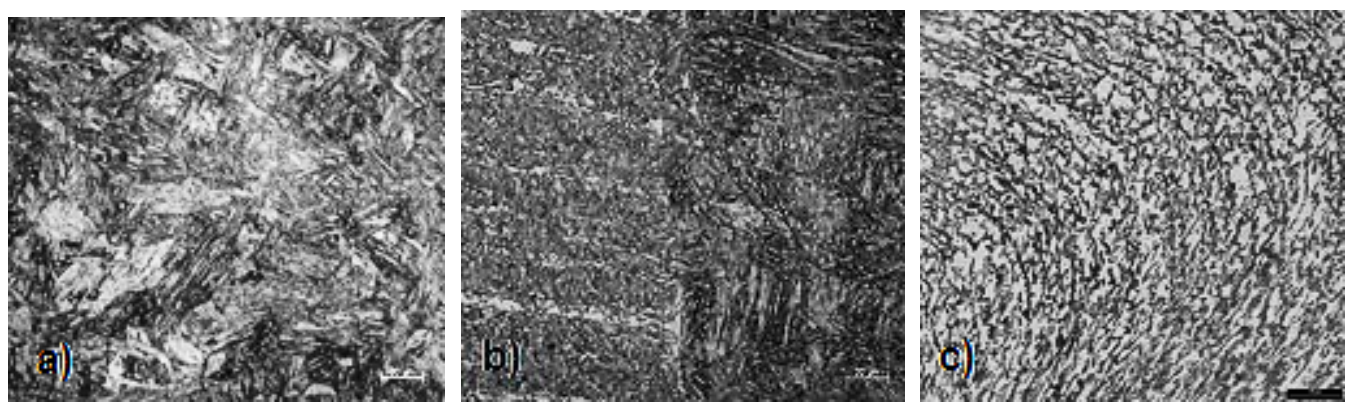

Figure 5: Optical micrographs of TRIP $780 \varphi=0.15$ a) fusion zone, b) HAZ, c) base metal. $50 x$

Base metal microstructure of steel TRIP 780 was composed of polygonal ferrite, bainite and retained austenite. The results of $\mathrm{X}$ ray diffraction analysis of base metal (Fig. 6) revealed that the initial microstructure was composed of $92.59 \%$ of ferrite Fe $\alpha$ and $7.41 \%$ of retained austenite $\mathrm{Fe} \gamma_{\mathrm{z}}$.

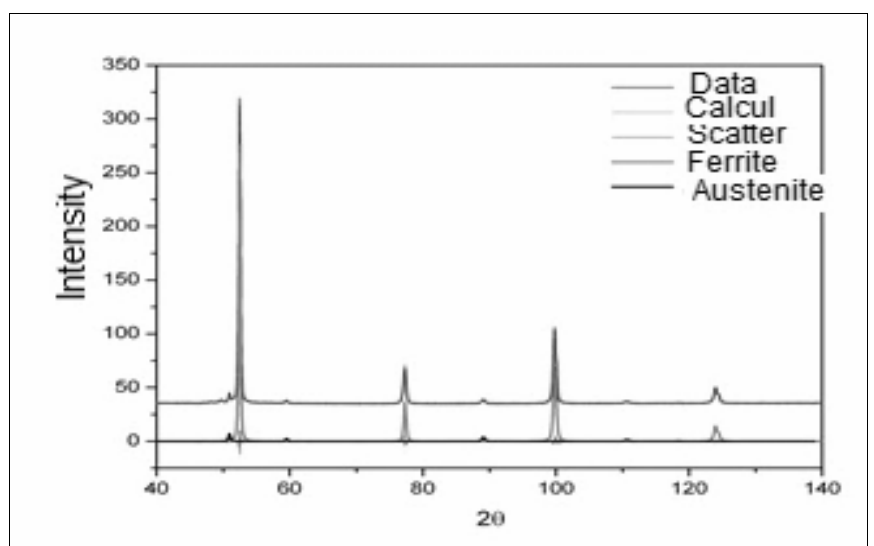

(a)

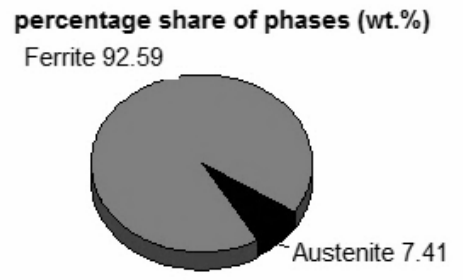

(b)

Figure 6: (a) TRIP 780 diffraction record and (b) base metal percentage share of Fea a Fe $\gamma_{z}$

The results of TEM analysis of fusion zone are shown in Fig. 7. In TEM observations lathy martensite was revealed. Fig. 8 presents spot diffraction spectrum of martensite tetragonal crystal lattice $\mathrm{Fe} \alpha^{\prime}$ with [111] directions. The microhardness profiles trough the welded joints are shown in Fig. 9. These measurements indicate that laser welding promotes significant increase in 
hardness in the area of fusion zone. Three microhardness profiles in Fig.9 correspond to specimens with three levels of straining. The highest hardness was exhibited by the specimen of weld joint with the highest strain value of $\varphi=0.15$, after that the specimen with the strain of $\varphi=0.12$ and finally the specimen with the lowest strain value of $\varphi=0.002$.

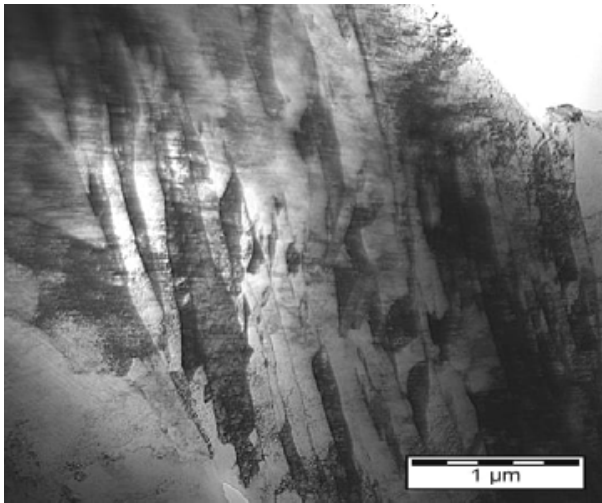

Figure 7: Grains of lathy

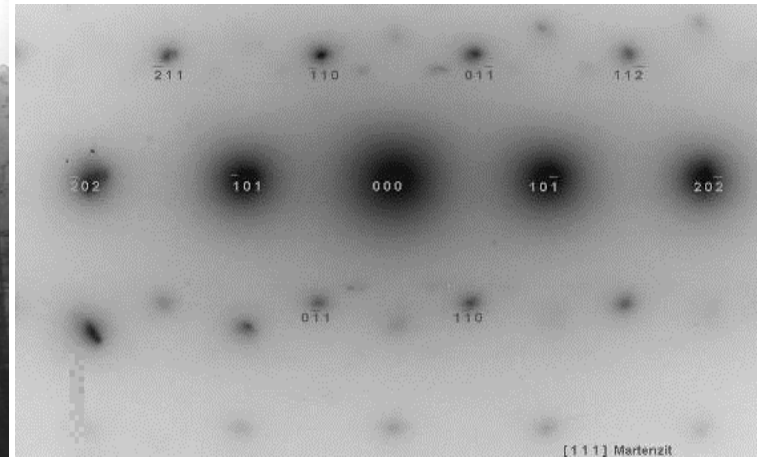

Figure 8: Diffraction spectrum of Fea' crystal lattice

martenzite of the fusion zone

The shift of the hardness profiles can be explained by specimens strengthening after deep drawing. Higher strain imposed higher strengthening both of the base metal and of the fusion zone. With regard to the complex base metal microstructure various strengthening mechanisms must be considered during deep drawing process. Seeing that the austenite portion before and after deep drawing was on the bottom of applied $\mathrm{X}$ ray diffraction method resolution border, it is impossible to evaluate if the TRIP effect or work hardening were dominant. The hardening of the fusion zone isn't as intensive as of base metal which can be attributed to the initial fusion zone structure predominantly composed of martensite. The scatter of hardness values in fusion zone essential for the weld joint with highest strain is relatively high what implies the presence of softer areas. From this study is not clear whether occurrence of martensite in fusion zone can be reduced by a careful selection of processing parameters during laser welding, which requires further investigation.

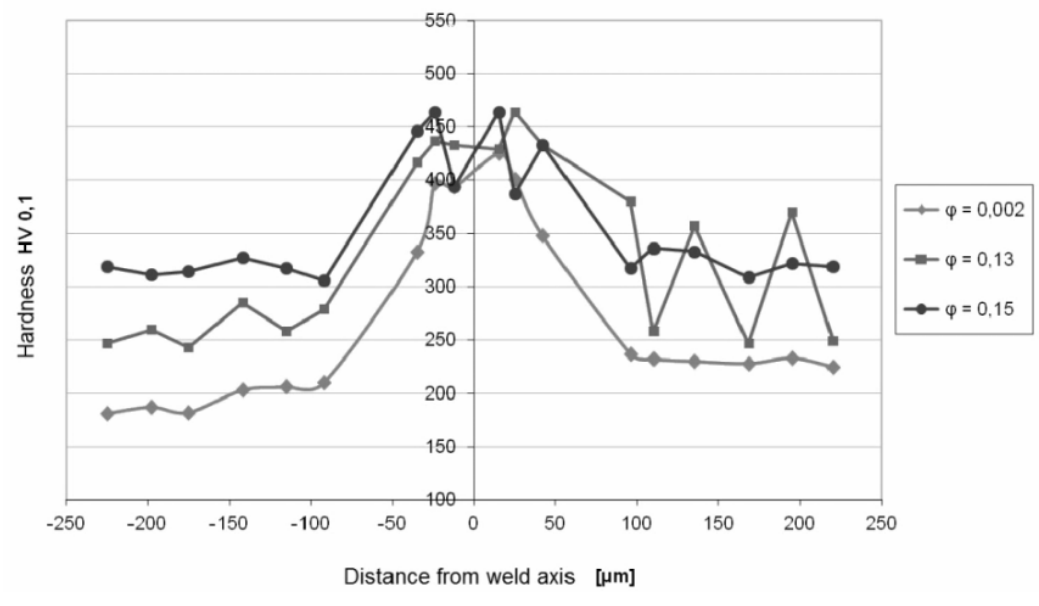


Fig. 9 Microhardness profiles of laser weld joints with various strain levels

\section{CONCLUSIONS}

The effect of weld joint straining on the final microstructure and properties of laser welded joints was investigated on high strength low carbon steel TRIP 780. Two sheets of dissimilar thickness of 1.0 and $1.2 \mathrm{~mm}$ were but welded by fiber solid state laser with the beam 0.7 $\mathrm{mm}$ in diameter and the modulated power to $8 \mathrm{~kW}$. Welded composite semiproduct was subsequently stamped at deep drawing. Three specimens with the strain value of $0.012,0.13$ and 0.15 were taken from the drawn cup and investigated by means of light microscopy, transmission electron microscopy and hardness profile measurements.

$\mathrm{X}$ ray diffraction analysis revealed that the microstructure of base metal before deep drawing was composed of ferrite $F e \alpha(92.59 \%)$ and of retained austenite $\mathrm{Fe} \gamma_{z}(7.41 \%)$. TEM observations confirmed that the fusion zone microstructure was essentially lathy martensite.

The macrostructure of welds after deep drawing remained compact, weld defects were not observed. Light microscopy of the strained weld microstructures revealed considerable differences of base metal and HAZ structure morphology related to applied strain values.

Microhardness measurements indicated that laser welding promoted significant increase in hardness in the area of fusion zone. This increase was to $35 \%$ by the specimen with lowest strain value.

Hardness profiles of welds were moved with respect to applied deformation. The highest hardness was exhibited by the specimen of the weld joint with the highest strain value $\varphi=0.15$. This shift of the hardness profiles can be explained by mechanical strengthening of specimens after deformation. Due to the complex strengthening mechanism of TRIP steels and the low content of the retained austenite, down on the resolution border, it is ambiguous to assign resultant strengthening to TRIP effect or work hardening.

\section{ACKNOWLEDGEMENT}

This work was supported by Scientific grant agency of the Ministry of Education of the Slovak Republic under the contract No. VEGA 1/0149/13.

\section{REFERENCES}

[1] Ready, John: LIA Handbook of Laser Materials Processing. Laser Institute of America, Magnolia Publishing, Inc., 2001, 713 pp., ISBN 0-941463-02-8

[2] ŽITŃANSKÁ, Veronika -- ĎURIČEK, Dušan -- ŠEVČIK, Peter: Technologické vlastnosti oceli určených pre zváranie prístrihov v automobilovom priemysle. Zvárač Roč. 9, č. 1. s. 14--17. ISSN 1336-5045.

[3] ĎURIČEK, Dušan - ŠEVČÍK, Peter - IŽDINSKÁ, Zita: Analýza vlastností laserových zvarových spojov TRIP ocele rôznym stupňom pretvorenia. Zborník abstraktov z 12 . Medzinárodnej konferencie Technológia $2011+\mathrm{CD}$ s plnými textami príspevkov, Bratislava, Nakladatel'stvo STU 2011, str. 386-393, ISBN 978-80-227-3545-2. 